\title{
BMJ Open Causes of premature death and their associated risk factors in the Golestan Cohort Study, Iran
}

\begin{abstract}
Mahdi Nalini, ${ }^{1,2}$ Ebele Oranuba, ${ }^{3}$ Hossein Poustchi, ${ }^{1,4}$ Sadaf G Sepanlou, ${ }^{1}$ Akram Pourshams, ${ }^{1,4,5}$ Masoud Khoshnia,, ${ }^{4,6}$ Abdolsamad Gharavi,, Sanford M Dawsey, ${ }^{7}$ Christian C Abnet, ${ }^{7}$ Paolo Boffetta, ${ }^{8}$ Paul Brennan, ${ }^{9}$ Masoud Sotoudeh, ${ }^{1,4}$ Arash Nikmanesh, ${ }^{1,4}$ Shahin Merat, ${ }^{1,5}$ Arash Etemadi, ${ }^{1,7}$ Ramin Shakeri, ${ }^{1,4}$ Amir Ali Sohrabpour, ${ }^{1}$ Siavosh Nasseri-Moghaddam, ${ }^{1,4}$ Farin Kamangar, ${ }^{4,10}$ Reza Malekzadeh ${ }^{1,4,5}$
\end{abstract}

To cite: Nalini M, Oranuba E, Poustchi $\mathrm{H}$, et al. Causes of premature death and their associated risk factors in the Golestan Cohort Study, Iran. BMJ Open 2018;8:e21479. doi:10.1136/ bmjopen-2018-021479

- Prepublication history and additional material for this paper are available online. To view please visit the journal (http:// dx.doi.org/10.1136/bmjopen2018-021479).

Received 2 January 2018 Revised 27 April 2018 Accepted 29 May 2018
Check for updates

(C) Author(s) (or their employer(s)) 2018. Re-use permitted under CC BY-NC. No commercial re-use. See rights and permissions. Published by BMJ.

For numbered affiliations see end of article.

Correspondence to Dr Farin Kamangar; farin.kamangar@morgan.edu and Professor Reza Malekzadeh; malek@tums.ac.ir

\section{ABSTRACT}

Objectives To examine the causes of premature mortality ( $<70$ years) and associated risk factors in the Golestan Cohort Study.

Design Prospective.

Setting The Golestan Cohort Study in northeastern Iran. Participants 50045 people aged 40 or more participated in this population-based study from baseline (2004-2008) to August 2017, with over 99\% success follow-up rate. Main outcome measures The top causes of premature death, HR and their $95 \% \mathrm{Cl}$ and population attributable fraction (PAF) for risk factors.

Results After 444168 person-years of follow-up (median of 10 years), 6347 deaths were reported, of which 4018 $(63.3 \%)$ occurred prematurely. Ischaemic heart disease (IHD) accounted for $33.9 \%$ of premature death, followed by stroke $(14.0 \%)$, road injuries $(4.7 \%)$, stomach cancer (4.6\%) and oesophageal cancer (4.6\%). Significant risk/ protective factors were: wealth score (HR for highest vs lowest quintile: 0.57 , PAF for lowest four quintiles vs top quintile: $28 \%$ ), physical activity (highest vs lowest tertile: 0.67 , lowest two tertiles vs top tertile: $22 \%$ ), hypertension $(1.50,19 \%)$, opium use $(1.69,14 \%)$, education (middle school or higher vs illiterate: 0.84 , illiterate or primary vs middle school or higher: $13 \%)$, tobacco use $(1.38,11 \%)$, diabetes $(2.39,8 \%)$ and vegetable/fruit consumption (highest vs lowest tertile: 0.87 , lowest two tertiles vs top tertile: $8 \%$ ). Collectively, these factors accounted for $76 \%$ of PAF in men and $69 \%$ in women.

Conclusion IHD and stroke are the leading causes of premature mortality in the Golestan Cohort Study. Enhancing socioeconomic status and physical activity, reducing opium and tobacco use, increasing vegetable/ fruit consumption and controlling hypertension and diabetes are recommended to reduce premature deaths.

\section{INTRODUCTION}

The loss of middle-aged family members is often devastating to the household, as families often rely on them as the primary breadwinners and caregivers. ${ }^{1}$ Premature death of a middle-aged person is thus often associated

\section{Strengths and limitations of this study}

- The Golestan Cohort Study is one of the largest and oldest population-based cohort studies in the Middle East, with over 50000 participants, and less than $1 \%$ loss to follow-up after 10 years.

- The accuracy of the follow-up and cause of death ascertainment, as well as availability of detailed and validated data on risk factors, are important strengths of this study.

- The cohort has no data on people younger than 40 years old, and the participants are mainly representative of the rural population.

with decreased income, poor mental health, loss of education and childhood and increased mortality in the affected families. ${ }^{2-4}$

The burden of premature mortality is particularly high in the low/middle-income countries (LMICs); over $80 \%$ of these premature deaths-defined as death before 70 years of age-occur in the LMICs. ${ }^{5}$ The WHO estimates that economic losses associated with premature deaths in LMICs is expected to increase to about US $\$ 7$ trillion by $2030 .^{6}$

While death is inevitable, extending life expectancy and avoiding premature death are quite feasible. ${ }^{7}$ For example, the life expectancy at birth in the USA in the short span between 1990 and 2015 increased from 75.4 to $78.8 .^{8}$ Reduction of premature deaths, a major public health focus, is one of the United Nation's sustainable development goals for $2030 .^{9}$

The causes of premature death vary widely between regions. ${ }^{10}$ Identification of the major causes of premature death and their associated risk factors in each population is crucial to health planning, policy development and budget prioritising. ${ }^{10}$ 
Iran is a middle-income country, with a relatively high burden of premature deaths. The average life expectancy for Iranian women and men were 73.2 and 70.5 years in 2004 and 76.6 and 74.5 years in 2015 , respectively. ${ }^{11} \mathrm{We}$ have used data from the Golestan Cohort Study (GCS), a very large prospective study in northeastern Iran, to examine the main causes of premature mortality and its associated risk factors. We have also determined and reported the burden of the major causes of premature death in terms of standard expected years of life lost (SEYLL) and the population attributable fraction (PAF) of significant modifiable risk factors.

\section{METHODS \\ GCS design}

The design and methods of the population-based GCS have been described previously. ${ }^{12}$ From 2004 to 2008, 50045 people aged 40-75 from Golestan Province were recruited in the study. Trained interviewers used structured questionnaires to collect data on demographics, medical history, lifestyle and physical examination. ${ }^{12}$ Data on the intensity, duration and frequency of physical activity were collected. Wealth score was calculated for each participant based on the ownership of household appliances and other variables such as house ownership, structure and size ${ }^{13}$ Height, weight and blood pressure were measured. Nutritional data were collected with a valid and reliable food frequency questionnaire (FFQ) that was designed for the GCS. ${ }^{14}$ Validity was assessed by comparing FFQ results with 24-hour diet recalls and biochemical markers in serum and urine. Reliability was tested using intraclass correlation coefficients between four FFQ results administrated to the same persons. ${ }^{14}$

\section{Follow-up and death cause ascertainment}

All study participants were followed annually. The GCS team completed a case review questionnaire during each phone call or home visit and recorded the vital status of the participants. If a death was reported, all clinical reports and hospital records were collected within the entire province and the neighbouring provinces and a verbal autopsy (estimation of death cause using signs and symptoms during the period leading up to death, in the absence of reliable medical records ${ }^{15}$ was completed if needed. Using the collected documents, two independent internists determined the cause of death based on the International Classification of Diseases 10th version (ICD-10) codes. The two codes were compared, and if they were different, a third more senior internist reviewed the data and made the final code.

\section{Statistical methods}

Continuous variables were expressed as mean (SD) and categorical variables as percentages. History of ischaemic heart disease (IHD), stroke and diabetes mellitus was considered positive if the study participant reported diagnosis by a physician. High blood pressure was defined as any of these conditions: systolic blood pressure $\geq 140 \mathrm{~mm}$ $\mathrm{Hg}$, diastolic blood pressure $\geq 90 \mathrm{~mm} \mathrm{Hg}$ or being known case of hypertension (diagnosed by a physician). Individuals were considered tobacco users if they had smoked or had chewed nass (a kind of smokeless tobacco ${ }^{12}$ ) at least once a week for a period of 6 months or more. Likewise, opium users or alcohol drinkers were defined as those who consumed these substances at least once a week or once a month, respectively, for a minimum of 6 months. Physical activity was categorised based on the metabolic equivalent of task per minute per week into tertiles. Wealth score was categorised into quintiles, and consumption of vegetables and fruits (grams/day) was categorised into tertiles.

The analysis of deaths by cause was carried out based on the WHO methods and data sources for country-level causes of death in 2000-2015. ${ }^{16}$ Accordingly, the top 10 causes of death were determined after redistribution of garbage codes, for example, ill-defined cardiovascular diseases (I10, I26.9, I46, I47.2, I49.0, I50, I51.4, I51.5, I51.6, I51.9 and I70.9), injuries undetermined whether intentional or unintentional (Y10-Y34, Y87.2), and ill-defined cancers (C76, C80, and C97), and symptoms, signs and ill-defined conditions (ICD10 codes R00-R94, R96-R99).

For the purpose of our analysis, death among people aged $<70$ years was considered premature. Follow-up time extended from the date of cohort enrolment to the date of premature death, age 70 years, loss to follow-up or 13 August 2017, whichever came first. We used the life table method to calculate the probability of reaching the age of 70 years for those who had reached age 40 . To do this, we calculated and multiplied the probabilities of survival for each year between ages 40 and 70 (ie, 40 to 41,41 to $42, \ldots, 69$ to 70 ). To determine the association between premature death with independent covariates, Cox proportional hazard regression models were used to estimate HRs and 95\% CIs. For this analysis, we excluded participants with age 70 years or older, and those with a history of chronic diseases (ie, IHD, stroke or cancer) at baseline. In the Cox models, unadjusted, age-adjusted and sex-adjusted and fully adjusted HRs were calculated for each covariate. In the mutual model, the HRs were adjusted for potential confounders including age at baseline, sex, ethnicity, marital status, place of residence, education, wealth score, history of alcohol, tobacco/nass and opium consumption, physical activity, body mass index, vegetables and fruit consumption, hypertension and diabetes.

We also calculated the PAF for significant modifiable covariates based on mutual regression models, using 'punaf' command in Stata. The reference distribution was set so that each participant was unexposed to the risk factor, or in the category of the risk factor associated with the lowest risk of premature death (eg, the highest quintile of wealth score, the highest tertile of physical activity, etc).

We report SEYLL as measure of burden disease due to premature mortality. To obtain SEYLL, we first calculated 
the difference between life expectancy and age of death for each deceased person, and then summed up all these differences; SEYLL $=\sum\left(y_{i}-x_{i}\right)$, where $y_{i}$ is the life expectancy and $x_{i}$ is age of death for deceased person i. Life expectancy at each age was obtained from the Global Burden of Diseases (GBD) Study. ${ }^{10}$ All statistical analyses were done with Stata statistical software, V.12 (StataCorp, College Station, Texas, USA).

\section{Patient and public involvement}

Prior to developing the study, the research group informed the local authorities and university officials, local physicians, elders and religious leaders about the aims of the GCS to gain their support. Local people and physicians were consulted about various exposures, as well as the appropriate ways of asking questions. For example, local people provided information about commonly consumed foods, types of housing used over decades and common jobs. All interviews, data and sample collection were done by interviewers trained from among the local population. Results of blood analyses (eg, cholesterol) were reported to cohort participants. All participants received cohort membership cards, which allowed them to use certain medical services for free in Atrak Clinic, a gastroenterology clinic established by the research team. Salient results of the GCS are routinely shared with the Ministry of Health, university officials, local physicians and the public.

\section{RESULTS}

The mean age (SD) of participants at baseline was 52.1 (8.9) years. Fifty-eight per cent were women, $74.4 \%$ were Turkmen, $79.9 \%$ lived in rural areas, $87.8 \%$ were married and $70.2 \%$ had no formal education (online supplementary appendix table S1). Of the 50045 cohort participants, $47547(95.0 \%)$ were younger than 70 years old, potentially at risk of premature death.

The follow-up duration up to age 70 years was 444168 person-years (median 10, IQR: 8.9-11.1, and maximum 14.2 years). During the follow-up, 6347 of the cohort members died and 439 were lost to follow-up. Of the reported deaths, $445(7.0 \%)$ occurred before age 50, $1937(30.5 \%)$ before 60 and $4018(63.3 \%)$ before the of age 70 . The probability of reaching the age of 70 , conditional on surviving to age 40 years, was $79.2 \%$.

The ICD-10 codes were determined for 5550 (87.4\%) of all cohort deaths. A final cause of death determination has not yet been completed for the remaining, more recent, deaths $(n=797)$. Table 1 shows the top 10 causes of death based on age categories. IHD was the leading cause of death in all age categories. Stroke was the second cause of death except for deaths that occurred younger than 50 , for which road injury was the second cause of death. With rising age, the proportion of deaths due to stroke increased while deaths due to road injury decreased. Of 169 premature deaths of road injury, 119 deaths occurred in men and 50 in women. The general classification of death causes is shown in online supplementary table S2.

Overall, communicable, maternal, prenatal and nutritional (CMPN) group of diseases accounted for 168 $(4.7 \%)$, non-communicable diseases (NCDs) for 3174 $(88.8 \%)$ and injuries for $234(6.5 \%)$ of premature deaths. In these three groups of disease, $50.0 \%, 64.4 \%$ and $81.8 \%$ of deaths occurred before age 70 , respectively.

Table 2 shows the HRs for the association between demographic and lifestyle risk factors and premature mortality. The risk of premature death was higher in men and unmarried participants, and in those with history of hypertension, diabetes, tobacco/nass use and opium consumption. The strongest associations were found for diabetes, opium consumption and hypertension, respectively. Risk of death increased $139 \%$ in diabetic participants (HR: 2.39, 95\% CI 2.15 to 2.65). Higher wealth, physical activity, education and consumption of vegetables and fruits were protective factors. Our results did not change materially after exclusion of deaths occurred in the first year of follow-up (online supplementary tables S3, S4), and after stratification by sex and age (online supplementary tables S5, S6)

The PAF for eight significant modifiable risk factors is shown in table 3. Wealth score had the highest PAF. The role of tobacco/nass use and opium consumption was more important among men, while the role of diabetes and hypertension was more pronounced in women. Collectively, these eight risk factors accounted for $76 \%$ of the PAF in men and $69 \%$ in women.

The total burden of premature mortality in the GCS was 107417 (SE=393) SEYLL. Among the 5550 deaths for which ICD-codes were determined, over $60 \%$ of the burden was due to only five causes: IHD, stroke, road injury, oesophageal cancer and stomach cancer (table 4).

\section{DISCUSSION}

In our study, among 50045 participants over 40 years old at the baseline, $63 \%$ of all deaths were premature, including $50 \%$ of CMPN, $64 \%$ of NCD and $82 \%$ of injury deaths. IHD and stroke were the leading causes of premature mortality and accounted for almost $50 \%$ of all causes of premature deaths and their burden based on SEYLL. Other significant causes of premature mortality in this study were road injuries, stomach cancer and oesophageal cancer. Higher wealth, physical activity, education and consumption of fruits and vegetables were protective factors. Conversely, hypertension, diabetes, opium and tobacco use increased risk. These factors are potentially modifiable, and together accounted for $69 \%$ and $76 \%$ of $\mathrm{PAF}$ in women and men, respectively.

The premature death rate in our study participants was very similar to the average premature death rate in all of Iran. Forty-year-old people in this cohort had a 79\% probability of reaching the age of 70 years. The survival probabilities of the entire Iranian population of comparable age were $75 \%$ and $80 \%$ in 2005 and 2015 , respectively. ${ }^{17}$ 


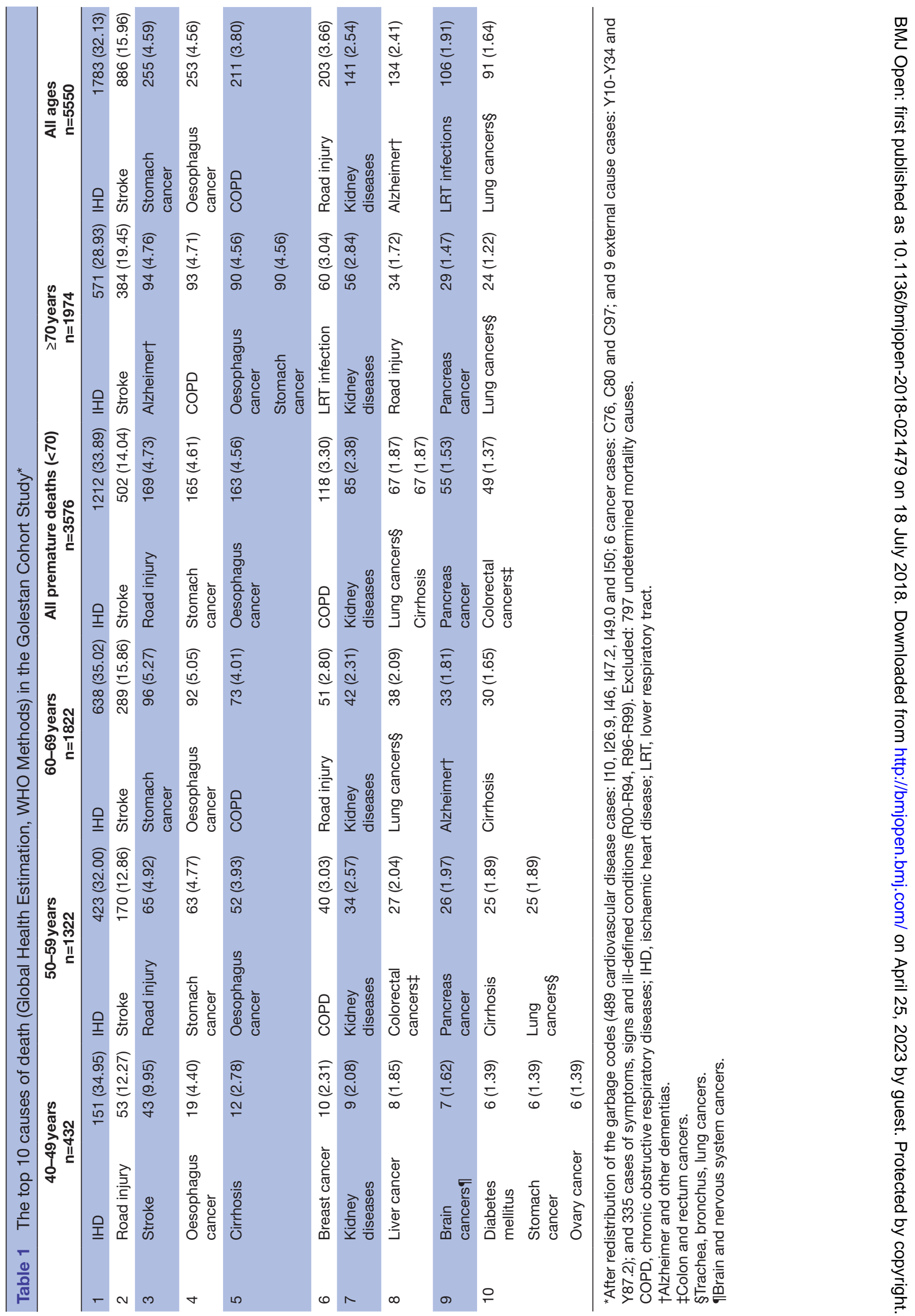


Table 2 HR for associations between demographic and lifestyle risk factors and premature mortality in the Golestan Cohort Study*

\begin{tabular}{|c|c|c|c|c|c|}
\hline Variable & $\begin{array}{l}\text { Prevalence } \\
\text { (w/o premature } \\
\text { death) } \\
n=40972\end{array}$ & $\begin{array}{l}\text { Prevalence } \\
\text { (premature death) } \\
n=3390\end{array}$ & $\begin{array}{l}\text { HR } \\
\text { (95\% Cl) } \\
\text { Crude }\end{array}$ & $\begin{array}{l}\text { HR } \\
\text { (95\% Cl) } \\
\text { Adjusted 1** }\end{array}$ & $\begin{array}{l}\text { HR } \\
\text { (95\% Cl) } \\
\text { Adjusted 2** }\end{array}$ \\
\hline \multicolumn{6}{|l|}{ Sex } \\
\hline Women (reference) & 24307 (59.33) & $1544(45.55)$ & 1 & & 1 \\
\hline Men & $16665(40.67)$ & $1846(54.45)$ & $1.74(1.63-1.87)$ & - & $1.37(1.24-1.51)$ \\
\hline \multicolumn{6}{|l|}{ Ethnicity } \\
\hline Turkmen (reference) & $30823(75.23)$ & $2614(77.11)$ & 1 & 1 & 1 \\
\hline Non-Turkmen & $10149(24.77)$ & 776 (22.89) & $0.97(0.90-1.06)$ & $0.96(0.89-1.04)$ & $1.00(0.92-1.09)$ \\
\hline \multicolumn{6}{|l|}{ Marital status } \\
\hline Married (reference) & $36616(89.37)$ & $2928(86.37)$ & 1 & 1 & 1 \\
\hline Other & $4356(10.63)$ & $462(13.63)$ & $1.50(1.36-1.65)$ & $1.37(1.23-1.52)$ & $1.17(1.05-1.31)$ \\
\hline \multicolumn{6}{|l|}{ Residence } \\
\hline Urban (reference) & $8058(19.67)$ & $597(17.61)$ & 1 & 1 & 1 \\
\hline Rural & 32914 (80.33) & $2793(82.39)$ & $1.24(1.14-1.36)$ & $1.27(1.16-1.38)$ & $0.91(0.82-1.01)$ \\
\hline \multicolumn{6}{|l|}{ Education } \\
\hline $\begin{array}{l}\text { No formal schooling } \\
\text { (reference) }\end{array}$ & 28009 (68.36) & $2523(74.42)$ & 1 & 1 & 1 \\
\hline Primary education & $7328(17.89)$ & $505(14.90)$ & $0.74(0.67-0.81)$ & $0.73(0.66-0.81)$ & $0.85(0.77-0.95)$ \\
\hline $\begin{array}{l}\text { Middle school or } \\
\text { higher }\end{array}$ & $5635(13.75)$ & $362(10.68)$ & $0.65(0.58-0.73)$ & $0.65(0.58-0.73)$ & $0.84(0.73-0.97)$ \\
\hline \multicolumn{6}{|l|}{ Wealth score } \\
\hline $\begin{array}{l}\text { First quintile } \\
\text { (reference) }\end{array}$ & $8391(20.48)$ & 986 (29.09) & 1 & 1 & 1 \\
\hline Second quintile & 7508 (18.32) & $741(21.86)$ & $0.84(0.77-0.93)$ & $0.86(0.78-0.94)$ & $0.91(0.82-1.00)$ \\
\hline Third quintile & $9007(21.98)$ & $651(19.20)$ & $0.63(0.57-0.70)$ & $0.64(0.58-0.71)$ & $0.70(0.63-0.77)$ \\
\hline Fourth quintile & $7858(19.18)$ & $560(16.52)$ & $0.62(0.56-0.69)$ & $0.63(0.57-0.70)$ & $0.72(0.64-0.80)$ \\
\hline Fifth quintile & $8208(20.03)$ & $452(13.33)$ & $0.46(0.41-0.52)$ & $0.48(0.43-0.54)$ & $0.57(0.50-0.65)$ \\
\hline \multicolumn{6}{|l|}{ Alcohol use } \\
\hline Never (reference) & $39685(96.86)$ & $3206(94.57)$ & 1 & 1 & 1 \\
\hline Ever used & $1287(3.14)$ & $184(5.43)$ & $1.65(1.42-1.91)$ & $1.20(1.03-1.40)$ & $1.04(0.89-1.22)$ \\
\hline \multicolumn{6}{|c|}{ Tobacco smoking/nass chewing } \\
\hline Never (reference) & $32887(80.28)$ & $2182(64.37)$ & 1 & 1 & 1 \\
\hline Ever used & $8078(19.72)$ & $1208(35.63)$ & $2.25(2.09-2.41)$ & $1.84(1.69-2.00)$ & $1.38(1.26-1.53)$ \\
\hline \multicolumn{6}{|l|}{ Opium consumption } \\
\hline Never (reference) & $34840(85.03)$ & $2320(68.44)$ & 1 & 1 & 1 \\
\hline Ever used & $6132(14.97)$ & $1070(31.56)$ & $2.60(2.42-2.79)$ & $2.18(2.02-2.35)$ & $1.69(1.55-1.85)$ \\
\hline \multicolumn{6}{|c|}{ Physical activity (MET min/week) } \\
\hline First tertile (Reference) & $12797(31.31)$ & $1567(46.32)$ & 1 & 1 & 1 \\
\hline Second tertile & $13158(32.19)$ & $1039(30.71)$ & $0.62(0.58-0.67)$ & $0.79(0.72-0.86)$ & $0.81(0.75-0.89)$ \\
\hline Third tertile & $14918(36.50)$ & $777(22.97)$ & $0.40(0.37-0.43)$ & $0.63(0.57-0.69)$ & $0.67(0.61-0.74)$ \\
\hline \multicolumn{6}{|l|}{ Body mass index $\left(\mathrm{kg} / \mathrm{m}^{2}\right)$} \\
\hline$<18.5$ & $1792(4.37)$ & $285(8.41)$ & $1.76(1.55-2.01)$ & $1.67(1.47-1.89)$ & $1.40(1.22-1.59)$ \\
\hline 18.5-24.9 (Reference) & $14506(35.41)$ & $1315(38.80)$ & 1 & 1 & 1 \\
\hline $25-29.9$ & $14010(34.20)$ & $1064(31.40)$ & $0.82(0.76-0.89)$ & $0.90(0.83-0.98)$ & $0.96(0.88-1.04)$ \\
\hline$\geq 30$ & $10660(26.02)$ & 725 (21.39) & $0.72(0.66-0.79)$ & $0.90(0.82-0.99)$ & $0.92(0.83-1.01)$ \\
\hline
\end{tabular}

Continued 
Table 2 Continued

\begin{tabular}{|c|c|c|c|c|c|}
\hline Variable & $\begin{array}{l}\text { Prevalence } \\
\text { (w/o premature } \\
\text { death) } \\
\mathrm{n}=40972\end{array}$ & $\begin{array}{l}\text { Prevalence } \\
\text { (premature death) } \\
n=3390\end{array}$ & $\begin{array}{l}\text { HR } \\
\text { (95\% Cl) } \\
\text { Crude }\end{array}$ & $\begin{array}{l}\text { HR } \\
\text { (95\% Cl) } \\
\text { Adjusted 1** }\end{array}$ & $\begin{array}{l}\text { HR } \\
\text { (95\% Cl) } \\
\text { Adjusted } 2^{\star *}\end{array}$ \\
\hline \multicolumn{6}{|c|}{ Vegetable/Fruit consumption (g/day) } \\
\hline First tertile (reference) & 13099 (32.53) & $1206(36.42)$ & 1 & 1 & 1 \\
\hline Second tertile & $13546(33.64)$ & $1092(32.98)$ & $0.86(0.79-0.93)$ & $0.87(0.80-0.95)$ & $0.95(0.88-1.04)$ \\
\hline Third tertile & 13627 (33.84) & $1013(30.59)$ & $0.75(0.69-0.82)$ & $0.74(0.68-0.80)$ & $0.87(0.80-0.95)$ \\
\hline \multicolumn{6}{|l|}{ High blood pressure } \\
\hline No (reference) & 25177 (61.45) & $1648(48.61)$ & 1 & 1 & 1 \\
\hline Yes & 15795 (38.55) & $1742(51.39)$ & $1.78(1.66-1.90)$ & $1.47(1.37-1.58)$ & $1.50(1.39-1.61)$ \\
\hline \multicolumn{6}{|l|}{ Diabetes mellitus } \\
\hline No (reference) & 38746 (94.57) & $2956(87.20)$ & 1 & 1 & 1 \\
\hline Yes & $2226(5.43)$ & $434(12.80)$ & $2.55(2.31-2.82)$ & $2.34(2.11-2.59)$ & $2.39(2.15-2.65)$ \\
\hline
\end{tabular}

${ }^{*}$ Exclude: age $\geq 70$ years at baseline and history of ischaemic heart disease, stroke or cancer.

**Adjusted 1: Adjusted for sex and age at enrolment; Adjusted 2: Adjusted for age at enrolment and all variables listed.

MET, metabolic equivalent of task.

Globally, in 2015, $54 \%$ of all deaths were premature, including $79 \%$ of CMPN, $43 \%$ of NCD and $82 \%$ of injury deaths. These estimates for high/low-income countries are substantially different: $27.5 \%$ and $80 \%$ for all deaths, $22 \%$ and $91 \%$ for CMPN, $26 \%$ and $62 \%$ for NCD and $58 \%$ and $91 \%$ for injury, respectively. ${ }^{18}$ In 2015 , the premature NCD death rate for Iran was estimated to be $35 \%$. For comparison, the percentage of all NCD deaths occurring under the age of 70 ranged from $17 \%$ to $18 \%$ in Italy, Japan, Sweden and Greece to more than $75 \%$ in Angola, Sierra Leone and the United Arab Emirates. ${ }^{19}$

Our findings are consistent with those of the GBD study, which showed IHD, stroke and road injuries are the three leading causes of premature deaths in Iran, ${ }^{20}$ as well as upper-middle-income countries. ${ }^{10}$ The GBD study, using years of life lost (YLLs) as a measure of premature mortality, showed the causes that contributed the most YLLs varied worldwide. For example, IHD and stroke were the leading causes for both sexes for 123 countries, including in China (stroke) and India (IHD); but the leading causes were interpersonal violence or lower respiratory infection in some locations in Latin America and the Caribbean; HIV/AIDS, malaria, diarrhoeal diseases, or lower respiratory infections across much of sub-Saharan Africa; road injury in Ecuador, Qatar, Oman and United Arab Emirates; diabetes in Jamaica, Mauritius and Fiji; neonatal preterm birth complications in Palestine; conflict in Syria, Yemen and Afghanistan; and self-harm in Greenland and South Korea. ${ }^{10}$

Table 3 Population attributable fraction (PAF) of significant modifiable risk factors (mutually adjusted) for premature mortality in the Golestan Cohort Study

\begin{tabular}{llll}
\hline Variable* & PAF (all) & PAF (women) & PAF (men) \\
\hline Education & $0.13(0.01-0.23)$ & $0.15(0.03-0.26)$ & $0.11(0.00-0.20)$ \\
Wealth score & $0.28(0.20-0.35)$ & $0.28(0.21-0.35)$ & $0.28(0.20-0.34)$ \\
Tobacco/nass use & $0.11(0.08-0.14)$ & $0.02(0.02-0.03)$ & $0.17(0.12-0.22)$ \\
Opium consumption & $0.14(0.12-0.17)$ & $0.07(0.06-0.09)$ & $0.19(0.16-0.22)$ \\
Physical activity & $0.22(0.17-0.28)$ & $0.18(0.12-0.23)$ & $0.26(0.20-0.31)$ \\
Vegetable and fruit consumption (g/day) & $0.08(0.02-0.13)$ & $0.08(0.03-0.14)$ & $0.07(0.02-0.12)$ \\
High blood pressure & $0.19(0.15-0.22)$ & $0.21(0.17-0.24)$ & $0.17(0.14-0.20)$ \\
Diabetes mellitus & $0.08(0.07-0.10)$ & $0.11(0.09-0.12)$ & $0.06(0.05-0.07)$ \\
All socioeconomic status $\dagger$ & $0.37(0.28-0.45)$ & $0.39(0.29-0.47)$ & $0.35(0.26-0.43)$ \\
All individual risk factors $\ddagger$ & $0.58(0.53-0.62)$ & $0.51(0.45-0.55)$ & $0.64(0.59-0.68)$ \\
All & $0.73(0.68-0.77)$ & $0.69(0.64-0.74)$ & $0.76(0.72-0.80)$ \\
\hline
\end{tabular}

*Variable (reference category): education (middle school or higher), wealth score (fifth quintile), tobacco/nass use (never), opium consumption (never), physical activity (third tertile), vegetable and fruit consumption (third tertile), high blood pressure (no), diabetes mellitus (no). †Education and wealth score.

$\ddagger$ Tobacco/nass use, opium consumption, physical activity, vegetable/fruit consumption, high blood pressure and diabetes mellitus. 
Table 4 Standard expected years of life lost (SEYLL) due to premature death in the Golestan Cohort Study

\begin{tabular}{lcr}
\hline Causes of premature death & SEYLL (SE) & \multicolumn{1}{c}{$\%$} \\
\hline Ischaemic heart diseases & $32466(218)$ & 33.74 \\
Stroke & $13004(135)$ & 13.52 \\
Road injury & $5160(89)$ & 5.36 \\
\hline Oesophageal cancer & $4301(78)$ & 4.47 \\
Stomach cancer & $4220(71)$ & 4.39 \\
Chronic obstructive pulmonary & $2972(59)$ & 3.09 \\
diseases & $2295(58)$ & 2.39 \\
Kidney diseases & $1866(55)$ & 1.94 \\
Cirrhosis of the liver & $1711(47)$ & 1.78 \\
\hline Trachea, bronchus, lung cancers & $1483(42)$ & 1.54 \\
\hline Pancreas cancer & $96219(376)$ & 100 \\
\hline All* & & \\
\hline
\end{tabular}

${ }^{\star}$ Exclude 797 non-determined ICD-codes.

Out of the 17 million premature deaths due to NCDs, $82 \%$ are in LMICs, of which $37 \%$ are caused by cardiovascular diseases. ${ }^{21}$ IHD and stroke have remained the leading causes of death globally in the last 15 years. ${ }^{22}$ In our study, about $90 \%$ of deaths were due to NCDs; of this, IHD and stroke accounted for $38 \%$ and $16 \%$ of deaths, respectively. According to WHO reports, between 2005 and 2015, at these ages, NCDs cause almost $80 \%-82 \%$ of all deaths globally; of this, $21.5 \%$ were IHD and $16 \%$ were stroke. ${ }^{18}$ In our study, death due to IHD played the most important role in premature NCD death. Also, we found that stomach cancer accounted for $5.2 \%$ and oesophageal cancer for $5.1 \%$ of NCD deaths, whereas these figures globally were $2.5 \%-3 \%$ and $1.6 \%-2 \%$, respectively. ${ }^{18}$ Our results are in line with other studies that have shown a high prevalence of oesophageal cancer $^{23}$ and gastric cancer ${ }^{24}$ in the northeast of Iran.

In 2013, Iran was the eighth highest country, among 186 countries, for road traffic mortality rate $(32.1$ per 100000 population).$^{25}$ Around 1.25 million people died from road traffic injuries, and up to 50 million people sustained non-fatal injuries as a result of road traffic accidents. ${ }^{25}$ In our study, $72.2 \%$ of all injuries were due to road injuries, compared with a global average of $30 \%{ }^{18}$ This result is consistent with a report by WHO, which showed that $58 \%$ of all injuries in Iran were due to road traffic injuries. ${ }^{26}$ Similar to our results, other studies in Iran showed deaths due to road accident were higher in men versus women, also death rates due to accidents in adults decreased with age. ${ }^{27} 28$

Our results showed the strong effects of socioeconomic factors on premature mortality. Lack of wealth and education accounted for $37 \%$ of all premature deaths, stronger than any other individual risk factors. A study of over 1.7 million participants from seven countries found that the independent association between socioeconomic status and premature mortality is comparable in strength and consistency to known risk factors such as hypertension, diabetes and smoking. ${ }^{29}$ The participants of our cohort were mostly from villages in a remote area of Iran, and $70 \%$ were entirely illiterate. This may be an important reason for observing high premature rates in this population.

We found a significant HR for premature mortality associated with the use of opium. Our findings are consistent with previous findings from some studies that have shown the association of long-term opium use with $\mathrm{IHD}^{30-32}$ and several cancers. ${ }^{31}{ }^{32}$ In fact, the very common consumption of opium by nearly $17 \%$ of the cohort members may be another reason for high rates of premature mortality in this population.

Overall, our results showed that the eight potentially modifiable risk factors are collectively associated with about $70 \%$ of the PAF of premature deaths. The European Prospective Investigation into Cancer and Nutrition (EPIC) cohort study ${ }^{33}$ showed that the PAF for premature mortality for smoking, diet, overweight or obesity, hypertension, physical inactivity and alcohol intake was $57 \%$. There is evidence of regional variation in the importance of risk factors, which are related to variations in the magnitude of association and differences in the prevalence of risk factors among regions. ${ }^{34}{ }^{35}$ For example, the magnitude of smoking in Golestan Province, one of the most prevalent areas for oesophagus cancer worldwide, is almost half of that reported from western countries. ${ }^{36}$ On the other hand, whereas in the EPIC cohort study in Western Europe, high alcohol intake ( $>2$ drink/day) was reported in $23 \%$ of participants and was a significant risk factor for premature death, ${ }^{33}$ in our study, reported alcohol consumption was not associated with premature death. This may be because a small proportion of the participants (only $3.45 \%$ ) used alcohol, and they used alcohol in amounts that are quite low compared with consumption averages in Western countries.

In recent decades, the Iranian policymakers have started to pay attention to the burden of different diseases. Yet more needs to be done. In Golestan Province, socioeconomic factors-such as education, safe drinking water, roads, access to electricity and natural gas for heating and cooking-have improved dramatically. ${ }^{38}$ Although there has been some decline in road traffic mortality rates because of police enforcement activities and promotion of the prehospital emergency system, Iran still has one of the highest rates in the world. ${ }^{20}$ Despite several interventions to reduce harm from opium use, the burden is still rising in the country. ${ }^{20}$ Evidence is mounting that opium is a carcinogen ${ }^{39}$ and increases mortality. ${ }^{31}$ If an international body, such as the International Agency for Research on Cancer/WHO recognises opium as a carcinogen, public awareness of opium's harmful effects will increase. Salt intake in the Iranian population is about two times the recommended level in Iran and it most likely plays an important role in the high prevalence of hypertension and cardiovascular premature mortality. ${ }^{40} 41$ A very 
important intervention that has been recently started is decreasing intake of salt, especially in bread which is the main food item in Iran. Also, taxation of cigarette and other tobacco products has recently been established by the Iranian Parliament.

To effectively prevent premature mortality, ongoing national efforts need to be strengthened and supplemented with effective innovative actions. Some of these actions include: using premature death as a performance measure at the national and provincial levels and setting appropriate targets, which offers policymakers a major opportunity for securing health system improvement and accountability ${ }^{42}$; use of fixed-dose combination (poly-pill) therapy for primary and secondary prevention of cardiovascular diseases, ${ }^{4344}$ based on simple and practical guidelines that involve non-physician health workers; infusing the culture with taking care of chronic diseases in the primary healthcare system; comprehensive research programmes about the health effects of opium use and opium control policies; and focusing on improving socioeconomic status as a national health strategy, alongside reduction of established risk factors.

This study has several strengths including its prospective design, the availability of data to adjust for confounders and the extremely low loss to follow-up rate. One of the most important strengths of our study is the accuracy of the follow-up and cause of death ascertainment. Our principal limitation is that the participants in the GCS are mainly representative of the rural Iranian population, and not the urban dwellers who presently make up $70 \%$ of the total Iranian population and who may have a different distribution of demographic and risk factors. Also, we had no data on people younger than 40 years old. And finally, we did not have data on some known risk factors such as dyslipidaemia and psychological factors.

\section{Conclusion}

The premature mortality rate of the GCS population is comparable with the average rate of Iran. IHD, stroke, road injury and stomach and oesophagus cancers are the leading causes of premature mortality. Substantial improvements in premature mortality rates should be possible by reducing the consumption of opium and tobacco, increasing physical activity, increasing consumption of fruits and vegetables and controlling high blood pressure and diabetes. Also, the growing wealth and education in this area will likely lower premature mortality. Further research, wide dissemination of gained knowledge and supplementing the activities of the health infrastructure will all be important to increasing life expectancy.

\section{Author affiliations}

${ }^{1}$ Digestive Diseases Research Center, Digestive Diseases Research Institute, Tehran University of Medical Sciences, Tehran, Iran

${ }^{2}$ Cardiovascular Diseases Research Center, Kermanshah University of Medical Sciences, Kermanshah, Iran

${ }^{3}$ Department of Public Health Analysis, School of Community Health and Policy,

Morgan State University, Baltimore, Maryland, USA
${ }^{4}$ Digestive Oncology Research Center, Digestive Diseases Research Institute, Tehran University of Medical Sciences, Tehran, Iran

${ }^{5}$ Liver and Pancreaticobiliary Disease Research Center, Digestive Diseases Research Institute, Tehran University of Medical Sciences, Tehran, Iran

${ }^{6}$ Golestan Research Center of Gastroenterology and Hepatology (GRCGH), Golestan University of Medical Sciences, Gorgan, Iran

${ }^{7}$ Metabolic Epidemiology Branch, Division of Cancer Epidemiology and Genetics, National Cancer Institute, NIH, Bethesda, Maryland, USA

${ }^{8}$ The Tisch Cancer Institute and Institute for Translational Epidemiology, Ichan School of Medicine at Mount Sinai, New York City, New York, USA

${ }^{9}$ Section of Genetics-Genetic Epidemiology Group, International Agency for Research on Cancer, Lyon, France

${ }^{10}$ Department of Biology, School of Computer, Mathematical, and Natural Sciences, Morgan State University, Baltimore, Maryland, USA

Acknowledgements We thank the study participants for their cooperation and the Behvarz for their continuous help.

Contributors Design of the study: RM, FK, AP, SMD, CCA, PBo, PBr, SM, SNM, AE, MN, EO; data acquisition: RM, HP, AP, MK, AG, MS, AN, SM, RS, AAS; data interpretation: MN, FK, EO, SGS; data analysis: MN and SGS, writing the manuscript: MN, EO, FK; critical revision: RM, SNM, AAS, RS, AE, SM, AN, MS, PBo, PBr, CCA SMD, AG, MK, AP, HP. All gave final approval and agree to be accountable for all aspects of this work. MN, FK and RM are the guarantors.

Funding This study was supported by Tehran University of Medical Sciences (grant number: 81/15), Cancer Research UK (grant number: C20/A5860), the NGIMS/NIH (grant number: UL1 GM118973), the NCl/NIH Intramural Research Program, and through various collaborative research agreements with the IARC.

Disclaimer The funding sources had no role in study design, data collection, data analysis, data interpretation or writing of the report.

Competing interests None declared.

Patient consent Not required.

Ethics approval The study protocol was approved by the ethical review committees of the Digestive Disease Research Institute of Tehran University of Medical Sciences, the US National Cancer Institute, and the International Agency for Research on Cancer.

Provenance and peer review Not commissioned; externally peer reviewed.

Data sharing statement No additional data are available.

Open access This is an open access article distributed in accordance with the Creative Commons Attribution Non Commercial (CC BY-NC 4.0) license, which permits others to distribute, remix, adapt, build upon this work non-commercially, and license their derivative works on different terms, provided the original work is properly cited, appropriate credit is given, any changes made indicated, and the use is non-commercial. See: http://creativecommons.org/licenses/by-nc/4.0/.

\section{REFERENCES}

1. Chen JT, Rehkopf DH, Waterman PD, et al. Mapping and measuring social disparities in premature mortality: the impact of census tract poverty within and across Boston neighborhoods, 1999-2001. J Urban Health 2006;83:1063-84.

2. Pande R, Ogwang S, Karuga R, et al. Continuing with "...a heavy heart" - consequences of maternal death in rural Kenya. Reprod Health 2015;12 Suppl 1:1742-4755.

3. Ellis J, Dowrick C, Lloyd-Williams M. The long-term impact of early parental death: lessons from a narrative study. J $R$ Soc Med 2013;106:57-67.

4. Bazile J, Rigodon J, Berman L, et al. Intergenerational impacts of maternal mortality: Qualitative findings from rural Malawi. Reprod Health 2015:12 Suppl 1:1742-4755.

5. World Health Organization. Noncommunicable diseases Fact sheet. 2017 http://www.who.int/mediacentre/factsheets/fs355/en/ (October 2017).

6. World Health Organization. Global action plan for the prevention and control of noncommunicable diseases 2013-2020. $2013 \mathrm{http}: / /$ apps.who.int/iris/bitstream/10665/94384/1/9789241506236_eng.pdf (September 2017).

7. Peto R, Lopez AD, Norheim OF. Halving premature death. Science 2014;345:1272. 
8. U.S. Department of Health and Human Services, Secretary Centers for Disease Control and Prevention, National Center for Health Statistics. Health, United States, 2016: With Chartbook on Long-term in Health. 2017 https://www.cdc.gov/nchs/data/hus/hus16.pdf\#015 (October 2017).

9. United Nations. Sustainable Development Goals, 17 goals to transform our world. 2015 http://www.un.org/sustainabledevel opment/es/mdgs/ (October 2017).

10. GBD 2016 Causes of Death Collaborators. Global, regional, and national age-sex specific mortality for 264 causes of death, 19802016: a systematic analysis for the Global Burden of Disease Study 2016. Lancet 2017;390:1151-210.

11. World Health Organization. Life expectancy. Data by country. 2016 http://apps.who.int/gho/data/node.main.688 (December 2017).

12. Pourshams A, Khademi H, Malekshah AF, et al. Cohort Profile: The Golestan Cohort Study--a prospective study of oesophageal cancer in northern Iran. Int J Epidemiol 2010;39:52-9.

13. Islami F, Kamangar F, Nasrollahzadeh D, et al. Socio-economic status and oesophageal cancer: results from a population-based casecontrol study in a high-risk area. Int J Epidemiol 2009;38:978-88.

14. Malekshah AF, Kimiagar M, Saadatian-Elahi M, et al. Validity and reliability of a new food frequency questionnaire compared to 24 $\mathrm{h}$ recalls and biochemical measurements: pilot phase of Golestan cohort study of esophageal cancer. Eur J Clin Nutr 2006;60:971-7.

15. Khademi H, Etemadi A, Kamangar F, et al. Verbal autopsy: reliability and validity estimates for causes of death in the Golestan Cohort Study in Iran. PLoS One 2010;5:e11183.

16. WHO methods and data sources for country-level causes of death 2000-2015: World Health Organization. 2017 http://www.who.int/ healthinfo/global_burden_disease/GlobalCOD_method_2000_2015. pdf?ua $=1$.

17. World Health Organization. Global Health Observatory data repository: Life tables by country, Iran. $2017 \mathrm{http}: / /$ apps.who.int/gho/ data/view.main.60760 (October 2017).

18. World Health Organization. Health statistics and information systems, Estimates for 2000-2015. 2017 http://www.who.int/healthinfo/global_ burden_disease/estimates/en/index1.html (October 2017).

19. World Health Organization. Global Health Observatory (GHO) data, Premature NCD deaths, Situation and trends:. 2017 http://www.who. int/gho/ncd/mortality_morbidity/ncd_premature/en/ (October 2017).

20. Moradi-Lakeh M, Sepanlou SG, Karimi SM, et al. Trend of SocioDemographic Index and Mortality Estimates in Iran and its Neighbors, 1990-2015; Findings of the Global Burden of Diseases 2015 Study. Arch Iran Med 2017;20:419-28.

21. World Health Organization. Cardiovascular Diseases (CVDs), Fact sheet. 2017 http://www.who.int/mediacentre/factsheets/fs317/en/ (October 2017).

22. World Health Organization. The top 10 causes of death, Fact sheet. 2017 http://www.who.int/mediacentre/factsheets/fs310/en/ (October 2017).

23. Gholipour M, Islami F, Roshandel G, et al. Esophageal cancer in golestan province, iran: a review of genetic susceptibility and environmental risk factors. Middle East J Dig Dis 2016;8:249-66.

24. Malekzadeh R, Derakhshan MH, Malekzadeh Z. Gastric cancer in Iran: epidemiology and risk factors. Arch Iran Med 2009;12:576-83.

25. Wolrd Health Organization. World health statistics 2017: monitoring health for the SDGs, Sustainable Development Goals. Geneva: World Health Organization; 2017. Licence: CC BY-NC-SA 3.0 IGO 2017.

26. World Health Organization. Regional Office for the Eastern Mediterranean. Islamic Republic of Iran health profile 2015. 2016
http://applications.emro.who.int/dsaf/EMROPUB_2016_EN_19265. pdf?ua=1 (October 2017)

27. Khorshidi A, Ainy E, Soori $\mathrm{H}$, et al. Iranian road traffic injury project: assessment of road traffic injuries in Iran in 2012. J Pak Med Assoc 2016;66:A172.1-A172.

28. Montazeri A. Road-traffic-related mortality in Iran: a descriptive study. Public Health 2004;118:110-3.

29. Stringhini S, Carmeli C, Jokela M, et al. Socioeconomic status and the $25 \times 25$ risk factors as determinants of premature mortality: a multicohort study and meta-analysis of 1.7 million men and women. Lancet 2017;389:1229-37.

30. Masoudkabir F, Sarrafzadegan N, Eisenberg MJ. Effects of opium consumption on cardiometabolic diseases. Nat Rev Cardiol 2013;10:733-40.

31. Khademi H, Malekzadeh R, Pourshams A, et al. Opium use and mortality in Golestan Cohort Study: prospective cohort study of 50,000 adults in Iran. BMJ 2012;344:e2502.

32. Sadeghian S, Graili P, Salarifar M, et al. Opium consumption in men and diabetes mellitus in women are the most important risk factors of premature coronary artery disease in Iran. Int $J$ Cardiol 2010:141:116-8.

33. Muller DC, Murphy N, Johansson M, et al. Modifiable causes of premature death in middle-age in Western Europe: results from the EPIC cohort study. BMC Med 2016;14:016-630.

34. O'Donnell MJ, Chin SL, Rangarajan S, et al. Global and regional effects of potentially modifiable risk factors associated with acute stroke in 32 countries (INTERSTROKE): a case-control study. Lancet 2016;388:761-75.

35. Rosengren A, Hawken S, Ounpuu S, et al. Association of psychosocial risk factors with risk of acute myocardial infarction in 11119 cases and 13648 controls from 52 countries (the INTERHEART study): case-control study. Lancet 2004;364:953-62.

36. Nasrollahzadeh D, Kamangar F, Aghcheli K, et al. Opium, tobacco, and alcohol use in relation to oesophageal squamous cell carcinoma in a high-risk area of Iran. $\mathrm{Br} \mathrm{J}$ Cancer 2008;98:1857-63.

37. Roshandel G, Sadjadi A, Aarabi M, et al. Cancer incidence in Golestan Province: report of an ongoing population-based cancer registry in Iran between 2004 and 2008. Arch Iran Med 2012;15:196-200.

38. Khademi H, Kamangar F. Esophageal cancer incidence trends in northeastern Iran: comparing rates over 36 years. Arch Iran Med 2012;15:194-5

39. Kamangar F, Shakeri R, Malekzadeh R, et al. Opium use: an emerging risk factor for cancer? Lancet Oncol 2014;15:e69-e77.

40. Mohammadifard N, Fahimi S, Khosravi A, et al. Advocacy strategies and action plans for reducing salt intake in Iran. Arch Iran Med 2012;15:320-4.

41. Fahimi S, Pharoah P. Reducing salt intake in Iran: priorities and challenges. Arch Iran Med 2012;15:110-2.

42. Smith PC, Mossialos E IP. Performance measurement for health system improvement: experiences. challenges and prospects: World Health Organization;2008 http://www.who.int/management/district/ performance/PerformanceMeasurementHealthSystemlmprovement2. pdf.

43. Webster R, Castellano JM, Onuma OK. Putting polypills into practice: challenges and lessons learned. Lancet 2017;389:1066-74.

44. Huffman MD, Xavier D, Perel P. Uses of polypills for cardiovascular disease and evidence to date. Lancet 2017;389:1055-65. 